\title{
Persistent delayed auditory memory and executive function deficits 5 years after West Nile Virus Encephalitis: A neuropsychological and neuroimaging single case study
}

\author{
${ }^{1}$ Department of Psychology, University of Regina, Regina, Canada \\ ${ }^{2}$ Functional Rehabilitation Program, Wascana Rehabilitation Centre, Regina, Canada \\ ${ }^{3}$ Division of Neurology, Regina General Hospital, Regina, Canada \\ ${ }^{4}$ Director-Neuropsychology Service, Wascana Rehabilitation Centre, Regina, Canada \\ Email: ${ }^{\text {simon.mccrea@rqhealth.ca }}$
}

Michelle M. Gagnon ${ }^{1}$, Thomas P. Robinson ${ }^{2}$, Mohammad S. Ijaz ${ }^{3}$, Simon M. McCrea ${ }^{4 *}$

Received 17 July 2012; revised 11 September 2012; accepted 21 September 2012

\begin{abstract}
There are presently no in-depth published neuropsychological studies of West Nile Virus (WNV) encephalitis patients that have been well-correlated with high resolution structural MRI. In this study a middleaged male who developed West Nile Virus encephalitis five years previously was examined three times over a two year period. We examined him with the Wechsler Adult Intelligence Scales-Fourth Edition and the Wechsler Memory Scale-Fourth Edition (WAIS-IV/WMS-IV) and Advanced Clinical Solutions battery supplemented by tests of attention, executive, motor and sensory functions. Neuroradiological imaging revealed hypodensities within the left hippocampus in the axial and coronal planes with T2-FLAIR MRI. The man was previously high functioning and although he had prior history of well-controlled epilepsy it seems unlikely that the epilepsy could fully account for the neuropathological changes. The patient had previously completed a demanding six year double science degree program before he became ill with WNV and he had been a successful manager and director of a research company. Delayed auditory memory scores were at least two standard deviation units below age expected levels and semantic fluency and Booklet Category Tests of executive function were also in the impaired range. Moreover the illness onset profile of muscle weakness, extreme fatigue, memory complaints as well as inability to carry out research projects involving planning on the job were highly consistent with WNV encephalitis. If the memory and executive function deficits had been premorbid manifestations of epilepsy it is unlikely he would have attained the levels he did educationally and occupationally. This left hippocampal lesion is characteristic of

"Corresponding author.
\end{abstract}

other encephalitic viral infections such as herpes simplex virus. To our knowledge this is the first lateralized WNV encephalitis medial temporal lobe patient in the published literature.

Keywords: West Nile Virus; West Nile Virus Neuroinvasive Disease; Encephalitis; Flaviviruses; Neuropsychological Profiles; Hippocampus; Delayed Auditory Memory; Executive Functions; Longitudinal Study; Diffusion Weighted Imaging MRI

\section{INTRODUCTION}

Sejvar and colleagues [1, p.478] noted that "...the longterm cognitive and functional outcomes in persons surviving West Nile virus illness remain incompletely understood...experiences with other flaviviruses suggests that persistent neurocognitive deficits may occur following West Nile virus encephalitis..." Sampson and Armbrustmacher [2] studied four autopsy cases from the initial 1999 greater metropolitan New York City outbreak. Microscopic mononuclear inflammation was found most consistently within the medulla and thalamus of autopsied patients however there were similar changes seen in the hippocampus. Sampson and Armbrustmacher note that in West Nile Virus (WNV) the encephalitis is usually focal and slight with no associated vasculitis [2]. In contrast, in other flaviruses, such as St. Louis encephalitis, the distribution of lesions is cortical whereas in WNV the inflammation is predominately subcortical. Other prominent symptoms such as fatigue and muscle weakness are consistent with cranial and/or spinal nerve root inflammation.

Sejvar et al. [1] found that WNV patients performed poorer on pattern recognition memory, and significantly more encephalitis patients versus West Nile poliomyelitis and meningitis patients had scores below the $15^{\text {th }}$ percen- 
tile on the Cambridge Neuropsychological Testing Automated Battery (CANTAB) [3]. Sejvar et al. similarly found that when compared to population-based normative data WNV patients were impaired on visual processing, executive function, and maintenance of vigilance [1]. These authors note that features of Parkinsonism are often found in WNV encephalitis and a review of the literature found a tropism of West Nile Virus for the basal ganglia. That is, prior studies by Owen et al. [4] have found that executive planning difficulties were a frequent factor associated with Parkinson's disease.

Sadek et al. [5] reported on a sample of $41 \mathrm{WNV}$ neuroinvasive disease patients tested with the Wide Range Achievement Test 3; Finger Tapping, Animal Fluency, Trail Making Test; Symbol Digit Modalities Test; Hopkins Verbal Learning Test-Revised; Digit Span and Mental Control; and Rey Complex Figure Test [6-11]. The domains of psychomotor speed, memory, and executive functioning showed average impairment ratings of 56, 48 and 36 percent respectively. Finger Tapping (dominant and nondominant hands) and Hopkins Verbal Learning Test-Revised (which is a test of word list learning) were significantly impaired as were performances on the Animal Fluency and Trail Making Test [5]. Sadek et al. found that one year after symptom onset, more than half of the sample had objectively measurable neuropsychological impairment in at least two cognitive domains [5]. This most recent study did not determine the nature of the disease progression or combine it with more thorough neuropsychological evaluations in conjunction with neuroimaging.

The purpose of our study was to a evaluate a formerly high-functioning man who contracted West Nile virus in-depth longitudinally. He had been unable to engage in his previous employment because of significant functional disability seven years after his infection. A comprehensive neuropsychological battery was used unlike small collections of ability and memory tests used in previous studies $[1,2,5,12]$ along with high resolution MRI. Extensive background, mental status examination, and educational and occupational attainment indicators were compiled and evaluated to rule out the unlikely possibility that a pre-existing case of well-managed epilepsy was accounting for the symptoms.

\section{METHODS}

A 47-year-old right-handed man was referred for a neuropsychological evaluation after complaining of memory problems, mental and physical fatigue, and whole body weakness. Ancillary symptoms included mid-lower back pain, difficulty in learning new things, inability to process scientific information and poor reading comprehension. The illness was heralded by the onset of a high fever associated with mosquito born WNV contracted 5 years prior to the first evaluation. The patient completed three evaluations over the course of 16 months.

A four month interval occurred between the first and second assessment and a full year interval occurred between the second and third assessment. The patient was diagnosed with WNV after working in and around marshlands. Within days of infection he suddenly developed fever, mental confusion, sleepiness, memory problems, and muscle weakness.

Subsequent to contracting the virus the patient took six weeks leave from work during which time he developed an encephalitic infection. His recollection of events surrounding his hospitalization for encephalitis was poor. After the hospitalization he stated that he could remember faces but not names. In the first two months of the illness he reported tingling sensations emanating from his feet all the way up the back of his neck along the spine that were painful to the touch. Over the next four years the patient worked intermittently. By year four after the illness onset he was unable to engage in any extended mental activity associated with work. Prior to contracting the virus, the patient was reportedly healthy except for absence seizure epilepsy. He contracted meningitis at the age of 9 months of age and began to have seizures at 18 months of age. His last seizure is reported to have occurred 10 years prior to becoming infected with WNV and his epilepsy had been well-controlled. The patient had seen a neurologist for his epilepsy regularly. A neurological exam performed several days before the first neuropsychological assessment provided a passing 29/30 on the Mini-Mental State Exam with no obvious neurological deficits.

The patient had completed 5 years of college and a twoyear diploma course amounting to 16 years of formal education. He received mostly A's and B's throughout his post-secondary studies. He was successfully employed in a mid-level management governmental position for 15 years and oversaw a small research staff. The patient was involved in the publication of technical science projects requiring specialized knowledge and refined written language skills. As part of his job he would do a considerable amount of public speaking; however, after the illness he found he was unable to do this anymore. If someone asked a question he would be unable to follow the thread of the discussion occurring just minutes before.

The patient demonstrated word finding difficulties and he no longer enjoyed movies since he was no longer able to follow the story-line. He was also unable to complete activities that he was previously competent doing within a reasonable amount of time. The patient Full Scale Intelligence Quotient using the Test of Premorbid Functioning and Simple Demographics model with the Advanced Clinical Solutions [13] was 114. Response validity 
parameters were all in the optimal range for all three testing sessions and there were no indications of malingering. Tables 1 and 2 indicate that intellectual functioning was largely spared at both the Wechsler Adult Intelligence Scale-Third and Fourth Edition (WAIS-III/IV) composite and subtest level. Tegretol, an anti-convulsant, and Clobazam, which is a benzodiazepine derivative, were prescribed for his epilepsy successfully for many years.

\section{RESULTS}

Learning, Memory, and Executive Functioning. The patient's mean age scaled score of 8 on the Information subtest was slightly below expected values for someone with above average education and intellectual functions. This pattern is sometimes seen with verbal memory retrieval problems [14]. At the initial assessment the patient scored in the very low range on Trial 1 ( $\mathrm{T}$ score $=$

Table 1. WAIS-III/IV index standard scores.

\begin{tabular}{|c|c|c|c|c|c|c|}
\hline & \multicolumn{2}{|c|}{ Exam 1} & \multicolumn{2}{|c|}{ Exam 2} & \multicolumn{2}{|c|}{ Exam 3} \\
\hline & Score & Percentile & Score & Percentile & Score & Percentile \\
\hline FSIQ & 100 & 50 & 109 & 73 & 109 & 73 \\
\hline Verbal Comprehension & 94 & 34 & 98 & 45 & 96 & 39 \\
\hline Perceptual Reasoning ${ }^{\mathrm{a}}$ & 104 & 61 & 116 & 86 & 112 & 79 \\
\hline Processing Speed & 112 & 79 & 112 & 79 & 115 & 73 \\
\hline
\end{tabular}

Note. WAIS = Wechsler Adult Intelligence Scale; A four month interval occurred between Exam 1 and Exam 2 and a full year interval occurred between Exam 2

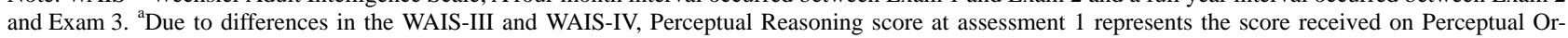
ganization on the WAIS-III. Standard scores have a mean of 100 and a standard deviation of 15.

Table 2. WAIS-III/IV subtest age scaled scores.

\begin{tabular}{|c|c|c|c|c|c|}
\hline Subtest & Exam 1 Score & Exam 2 Score & Exam 3 Score & Change Score & Mean Score \\
\hline \multicolumn{6}{|l|}{ Verbal Comp. Subtests } \\
\hline Similarities & 10 & 10 & 9 & -1 & 9.66 \\
\hline Vocabulary & 9 & 11 & 11 & +2 & 10.33 \\
\hline Information & 8 & 8 & 8 & 0 & 8.00 \\
\hline Comprehension & 11 & 10 & 12 & +1 & 11.00 \\
\hline \multicolumn{6}{|l|}{ Perceptual Reasoning } \\
\hline Block Design & 13 & 10 & 13 & 0 & 12.00 \\
\hline Matrix Reasoning & 13 & 13 & 13 & 0 & 13.00 \\
\hline Visual Puzzles & - & 15 & 10 & -5 & 12.50 \\
\hline Figure Weights & - & 13 & 13 & 0 & 13.00 \\
\hline Picture Completion & 7 & 9 & 8 & +1 & 8.00 \\
\hline Picture Arrangement & 8 & - & 10 & +2 & 9.00 \\
\hline Object Assembly & 12 & - & 11 & -1 & 11.50 \\
\hline \multicolumn{6}{|l|}{ Verbal Working Memory } \\
\hline Digit Span & 13 & 11 & 13 & 0 & 12.33 \\
\hline Arithmetic & 10 & 11 & 11 & +1 & 10.66 \\
\hline Letter Number Sequencing & 9 & 10 & 9 & 0 & 9.33 \\
\hline \multicolumn{6}{|l|}{ Processing Speed } \\
\hline Symbol Search & 14 & 13 & 15 & +1 & 14.00 \\
\hline Digit-Symbol Coding & 11 & 11 & 10 & -1 & 10.66 \\
\hline Cancellation & - & 11 & 11 & 0 & 11.00 \\
\hline
\end{tabular}

Note. Verbal Comp. subtests = Verbal comprehensions subtests; Change score $=($ Exam 3 - Exam 1 Score $)$; Scores are age scaled scores with a mean of 10 and a standard deviation of 3. A four month interval occurred between Exam 1 and Exam 2 and a full year interval occurred between Exam 2 and Exam 3. 
35) and Total Recall $(T=34)$ of the California Verbal Learning Test-II and in the very low range on Delayed Free Recall $(T=32)$ of the Brief Visuospatial Memory Test-Revised [15,16]. These measures evaluate verbal and nonverbal memory; respectively. At the initial assessment the patient scored in the very low range on Letter Fluency $(T=35)$ which is a measure of phonemic fluency. He also scored in the very low range on the Wisconsin Card Sorting Test's Failure to Maintain Set $(\mathrm{T}=33)$ which is a measure of persistence [17]. Finally at the initial assessment the patient scored in the very low range on the Booklet Category Test $(\mathrm{T}=35)$ which is a measure of concept formation [18].

Ability-memory comparisons were undertaken using the General Ability Index from the WAIS-IV [19]. Tables $\mathbf{3}$ and $\mathbf{4}$ reveal that unusually low scores on Auditory Memory at the second assessment did not improve significantly 1 year later at the third assessment. It seems unlikely that the patient would have been able to complete an advanced level of studies in university and prepare graduate-level technical science publications with Auditory Memory functions within ranges that would be typical of person's with intellectual disabilities. At exam 3 the patient's Logical Memory I and II age scaled scores were 8 and 7 and within the normal range. Whereas Verbal Paired Associates I and II age scaled scores were 4 and 3 respectively.

At exam 3 on Delayed Memory the age scaled scores for Logical Memory II, Verbal Paired Associates II, Designs II, Visual Reproduction II were 7, 3, 6, 6 respectively. This suggests that the deficit was verbal and specifically associated with delay trials of Verbal Paired Associates. Verbal Paired Associates II demonstrated a three age scaled score point drop in performance in the 1 year interval from July 2010 to August 2011 (Time 2 Actual Predicted Difference $=-5$, critical value $=3.16$, base rate in standardization sample $=1 \%$ ). At the second assessment performance on the Oral Symbol Digit Modalities Test $(T=34)$, which is a measure of oromotor functions, was in the very low range. At the second assessment, performance on the Wisconsin Card Sorting Test's Failure to Maintain Set $(T=30)$ remained in the extremely low range. Performance on the Booklet Category Test ( $\mathrm{T}$
= 35) similarly remained in the very low range.

At the third assessment, performance on Semantic Fluency $(T=33)$ was in the very low range. Performance on the Booklet Category Test $(\mathrm{T}=35)$ was similarly in the very low range. At all three assessment periods there were no obvious manual motor deficits that could be attributed to the effects of WNV (e.g., Finger Tapping, Grooved Pegboard and Grip strength) [7]. There were, however, some indications of sensory deficits. The patient scored at the 5th percentile on the Smell Identification Test [20] at the third assessment.

Achievement. Overall the results of achievement testing reveal sparing of academic skills with specific strengths in Math Computation consonant with the patient completing advanced mathematics courses at the university level (See Table 5).

Personality Functioning. The patient completed the 344-item Personality Assessment Inventory (PAI) at the first assessment [21]. There were elevations on the PAI Somatic Complaints $(T=76)$ subscale suggestive of significant concerns about impairment arising from bodily concerns. The Minnesota Multiphasic Personality Inventory-2 Restructured Form (MMPI-2-RF) [22] was administered at the third assessment and there were elevations on Low Positive Emotions $(T=76)$ and unusually low scores on the Hypomanic Activation $(\mathrm{T}=33)$ congruent with anhedonia and reduced activity level.

Affect and Mood Functioning. Depression, anxiety, and hopelessness were also evaluated at each session using the Beck Inventories [23-25]. During the period between the second and third assessments the patient was prescribed Cymbalta and Buproprion which appears to have hastened reduction in depressive symptomatology. This finding argues against the alternative interpretation that depression was directly responsible for mediating the poor memory performances. Based on his medical history there were no premorbid pathological personality or mood disorder indicators that might explain the pattern of neuropsychological test results (See Table 6).

\section{DISCUSSION}

We described the long-term effects of West Nile Virus in

Table 3. WMS-IV index standard scores.

\begin{tabular}{cccccc}
\hline & \multicolumn{3}{c}{ Exam 2 } & \multicolumn{2}{c}{ Exam 3 } \\
\cline { 2 - 5 } & Score & Percentile & Score & 74 & Percentile \\
\hline Auditory Memory & 69 & 2 & 89 & 4 \\
Visual Memory & 90 & 25 & 73 & 115 & 23 \\
Visual Working Memory & 109 & 13 & 87 & 19 \\
Immediate Memory & 83 & 2 & 69 & 2 \\
Delayed Memory & 70 & &
\end{tabular}

Note. WMS-IV = Wechsler Memory Scale-IV. 
Table 4. WMS-IV ability-memory standard score comparisons.

\begin{tabular}{|c|c|c|c|c|c|c|}
\hline & \multicolumn{3}{|c|}{ Exam 2} & \multicolumn{3}{|c|}{ Exam 3} \\
\hline & Predicted Value & Obtained Value & $\begin{array}{l}\text { Frequency in } \\
\text { Sample }\end{array}$ & Predicted Value & Obtained Value & $\begin{array}{c}\text { Frequency in } \\
\text { Sample }\end{array}$ \\
\hline Auditory Memory & 104 & 69 & $<1 \%$ & 102 & 74 & $2 \%$ \\
\hline Visual Memory & 104 & 90 & ns & 102 & 89 & ns \\
\hline Visual Working Memory & 105 & 109 & ns & 102 & 115 & ns \\
\hline Immediate Memory & 105 & 83 & $<3 \%$ & 102 & 87 & ns \\
\hline Delayed Memory & 104 & 70 & $<1 \%$ & 102 & 69 & $1 \%$ \\
\hline
\end{tabular}

Note. WMS-IV = Wechsler Memory Scale-IV; ns = non-significant

Table 5. WRAT-IV index standard scores.

\begin{tabular}{ccccccc}
\hline & \multicolumn{2}{c}{ Exam 1 } & \multicolumn{2}{c}{ Exam 2 } & \multicolumn{2}{c}{ Exam 3 } \\
\cline { 2 - 7 } & Score & Percentile & Score & Percentile & Score & Percentile \\
\hline Word Reading & 105 & 63 & 96 & 39 & 102 & 55 \\
Sentence Comprehension & 92 & 30 & 112 & 79 & 94 & 34 \\
Spelling & 118 & 88 & 117 & 87 & 118 & 88 \\
Math Computation & 136 & 99 & 126 & 96 & 136 & 99 \\
\hline
\end{tabular}

Note. WRAT-IV = Wide Range Achievement Test-IV.

Table 6. BDI, BAI, and BHS scores.

\begin{tabular}{|c|c|c|c|c|c|c|}
\hline & \multicolumn{2}{|c|}{ Exam 1} & \multicolumn{2}{|c|}{ Exam 2} & \multicolumn{2}{|c|}{ Exam 3} \\
\hline & Score & Description & Score & Description & Score & Description \\
\hline $\mathrm{BDI}^{\mathrm{a}}$ & 19 & Mild & 21 & Moderate & 5 & Minimal \\
\hline BAI & 1 & Minimal & 7 & Minimal & 8 & Minimal \\
\hline BHS & 2 & Minimal & 4 & Mild & 2 & Minimal \\
\hline
\end{tabular}

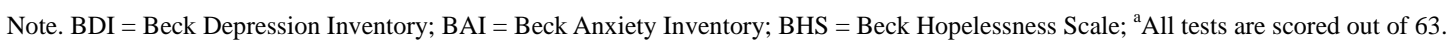

a 47-year-old male. In addition to extensive neuropsychological examination, we included neuroimaging results allowing for identification of structural changes within the brain. (See Figures 1-3).

The patient's neurocognitive presentation was primarily characterized by executive dysfunction (particularly in persistence and concept formation) and by memory deficits (specifically, delayed verbal memory). While achievement was not found to be negatively affected, the consequences of the patient's memory impairment were severe to the point of interfering with his ability to fulfill his job duties and perform at the level expected of person with his level of education.

Other researchers have identified fatigue and muscle weakness as a consequence of WNV, and that was also salient for our patient. He also demonstrated difficulty in oromotor functions, suggesting that persistent, long-term motor deficits and physical concerns are present. The patient did not show any Parkinsonian symptoms or neurotropism of the basal ganglia (e.g., no ganglia imaging abnormalities) that have been previously reported in pa- tients with WNV $[1,26]$. However, executive planning difficulties, a frequent feature of Parkinson's [4] were present in this patient.

Neuroimaging results highlight hypodensities within the left hippocampus in the axial and coronal planes. This hippocampal damage is consistent with the patient's demonstrated memory impairments. Hippocampal lesions are characteristic of other encephalitic viral infections such as herpes simplex virus [26]. The herpes simplex virus in the encephalitic form preferentially affects the medial temporal and orbital parts of the frontal lobes including the limbic cortex [27]. The frontal lobes are involved in planning and executive functions and the medial temporal lobes are involved in consolidating verbal and nonverbal memories [27]. The results suggest patent damage to the left temporal lobe and possible cortical infiltration of the virus into the frontal gray matter or ganglia; which was not evident neuroradiologically but might show up in other patients on autopsy [1,2].

The design of this study allowed for examination of the long-term sequelae of WNV, which has not been 


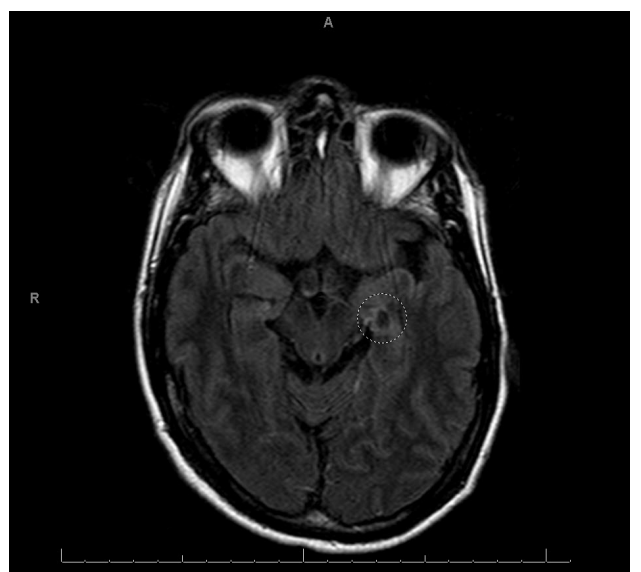

Figure 1. T2 FLAIR axial MRI image illustrating a hypodensity within the left anterior ventral hippocampus. Notice that there is no corresponding hypodensity within the right hippocampus. According to neuroradiological convention left is right and right is left. See the dotted circle in the left hemisphere.

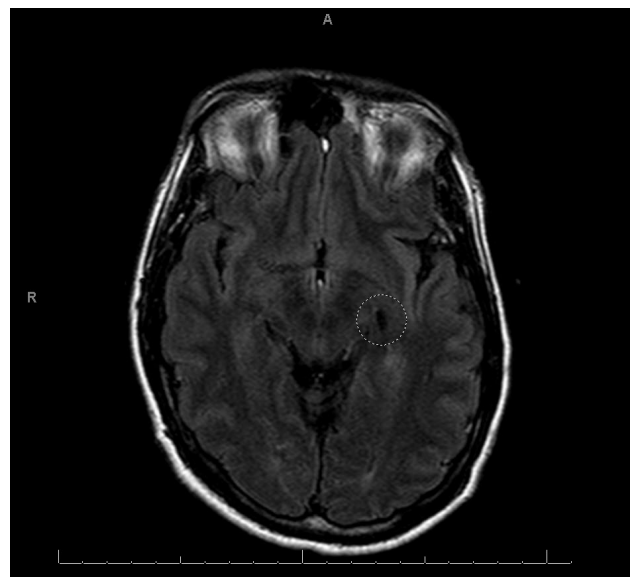

Figure 2. T2 FLAIR axial MRI image illustrating a hypodensity within the left anterior dorsal hippocampus.

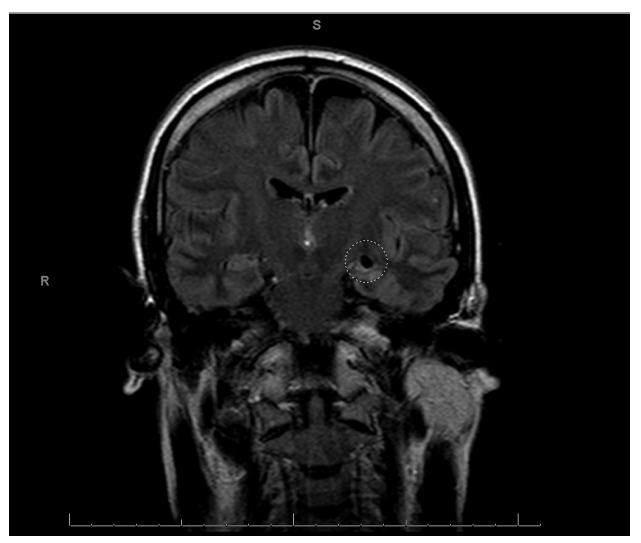

Figure 3. T2 FLAIR coronal MRI image illustrating a hypodensity at maximal diameter within the left hippocampus. extensively studied in previous research. The relatively few improvements that were found between initial testing and both subsequent testing exams, paired with the length of time since initial infection, suggest that persistent, neurocognitive deficits may occur in patients affected by WNV. Few improvements were seen between testing times, and the worsening oromotor and mental flexibility functioning from one assessment to the next as well as lack of improvement in concept formation suggest that there could be mildly active neurodegenerative processes.

Chronic epilepsy can often have adverse effects including mesial temporal sclerosis that can result in atrophy and ischemic changes [27]. However usually these changes show up as hyperintensity on T2-imaging and extensive medial temporal atrophy does not usually occur in patients with well-controlled seizures [27]. Moreover we hypothesize that it would be highly unlikely that our patient would have been able to achieve educationally and occupationally what he did if his left temporal lesion pre-existed the WNV infection. Functional impairment has been seen as being particularly prevalent in individuals with WNV neuroinvasive disease. Consistent with the findings of other researchers [1], quality of life was affected in this patient, as seen through psychosocial morbidity and impaired ability to work. To our knowledge, this is the first case demonstrating lateralized hypodensity in the hippo-campus. The significant neurocognitive deficits and the continued worsening of certain neurocognitive function 5 years following initial infection emphasize the enduring consequences of WNV.

\section{ACKNOWLEDGEMENTS}

This research was approved by the Research and Performance Support institutional review committee of the Regina Qu'Appelle Health Region at the Wascana Rehabilitation Centre in Regina, Canada. All research participants provided their informed written consent in accordance with the Declaration of Helsinki. This study was conducted in accordance with the principles of the Canadian Tri-Council Policy Statement: Ethical Conduct for Research Involving Humans. We thank the research participants for their involvement with our study. Dr. Gregor Jason provided helpful discussions of the individual participant's neuropsychological evaluations.

Joan Harmsworth-Dow of the Wascana Rehabilitation Centre's Health Science Library provided assistance with literature searches. Ms. Marlene Schick and Ms. Mercedes Will kindly offered administrative support during this study. The authors of this article report no conflict of interest.

\section{REFERENCES}

[1] Sejvar, J.J., Curns, A.T., Welburg, L., Jones, J.F., Lundgren, L.M., Capuron, L., Pape, J., Reeves, W.C. and Campbell, G.L. (2008) Neurocognitive and functional 
outcomes in persons recovering from West Nile Virus illness. Journal of Neuropsychology, 2, 477-499. doi:10.1348/174866407X218312

[2] Sampson, B.A. and Armbrustmacher, V. (2001) West Nile Virus encephalitis: The neuropathology of four fatalities. Annals of the New York Academy of Sciences, 951, 172178. doi:10.1111/j.1749-6632.2001.tb02695.x

[3] Sahakian, B.J. and Owen, A.M. (1992) Computerized assessment in neuropsychiatry using CANTAB: Discussion paper. Journal of the Royal Society of Medicine, 85, 399-402.

[4] Owen, A.M., James, M., Leigh, P.N., Summers, B.A., Marsden, C.D., Quinn, N.P., Lange, K.W. and Robbins, T.W. (1992) Fronto-striatal cognitive deficits at different stages of Parkinson's disease. Brain, 115, 1727-1751. doi:10.1093/brain/115.6.1727

[5] Sadek, J.R., Pergam, S.A., Harrington, J.A., Echevarria, L.A., Davis, L.E., Goade, D., Harnar, J., Nofchissey, R.A., Sewell, C.M., Ettstad, P. and Haaland, K.Y. (2010) Persistent neuropsychological impairment associated with West Nile Virus infection. Journal of Clinical and Experiental Neuropsychology, 32, 81-87.

[6] Wilkinson, G. (1993) Wide range achievement test 3. Psychological Assessment Resources, Wilmington.

[7] Heaton, R.K., Miller, W., Taylor, M.J. and Grant, I. (2007) Revised comprehensive norms for an expanded halsteadreitan battery. Psychological Assessment Resources, Wilmington.

[8] Smith, A. (1973) Symbol digit modalities test. Western Psychological Services, Los Angeles.

[9] Brandt, J. and Benedict, R.H. (2001) Hopkins verbal learning test-Revised. Psychological Assessment Resources, Odessa.

[10] Wechsler, D. (1997) Wechsler memory scale. 3rd Edition, The Psychological Corporation, San Antonio.

[11] Meyers, J.E. and Meyers, K. (1995) Rey complex figure test and recognition trial: Professional manual. Psychological Assessment Resources, Odessa. doi:10.5402/2011/123173

[12] Kelley, T.W., Prayson, R.A., Ruiz, A.I., Isada, C.M. and Gordon, S.M. (2003). The neuropathology of West Nie Virus meningoencephalitis: A report of two cases and a review of the literature. American Journal of Clinical Pathology, 119, 749-753. doi:10.1309/PU4R76JJMG1F81RP

[13] NCS Pearson (2009) Advanced clinical solutions for
WAIS-IV and WMS-IV: Administration and scoring manual. Psychological Corporation, San Antonio.

[14] Lezak, M.D., Howieson, D.B. and Loring, D.W. (2004) Neuropsychological assessment. 4th Edition, Oxford University Press, New York.

[15] Delis, D., Kaplan, E., Kramer, J. and Ober, B. (2000) California verbal learning Test-II. The Psychological Corporation, San Antonio.

[16] Benedict, R.H.B. (1997) Brief visuospatial memory test -Revised: Professional manual. Psychological Assessment Resources, Odessa.

[17] Heaton, R.K., Chelune, G.J., Talley, J.L., Kay, G.G. and Curtiss, G. (1993) Wisconsin card sorting test manual: Revised and expanded. Psychological Assessment Resources, Odessa.

[18] Defilippis, N., and McCambell, E. (1991) The booklet category test. Psychological Assessment Resources, Odessa.

[19] Wechsler, D. (2008) Wechsler adult intelligence scale, 4th Edition, The Psychological Corporation, San Antonio.

[20] Doty, R.L. (1995) The smell identification test administration manual. 3rd Edition, Sensonics, Haddon Heights.

[21] Morey, L.C. (1991) The personality assessment inventory professional manual. Psychological Assessment Resources, Odessa.

[22] Tellegen, A. And Ben-Porath, Y.S. (2008) MMPI-2-RF technical manual. University of Minnesota Press, Minneapolis.

[23] Beck, A.T., Steer, R.A. and Brown, G.K. (1996) Manual for the beck depression inventory-II. The Psychological Corporation, San Antonio.

[24] Beck, A.T. and Steer, R.A. (1990) Manual for the beck anxiety inventory. The Psychological Corporation, San Antonio.

[25] Beck, A.T. and Steer, R.A. (1993) Manual for the beck hopelessness scale. The Psychological Corporation, San Antonio.

[26] Kapur, N., Barker, S., Burrows, E.H., Ellison, D., Brice, J., Illis, L.S., Scholey, K., Colbourn, C., Wilson, B. and Loates, M. (1994) Herpes simplex encephalitis: Longterm magnetic resonance imaging and neuropsychological profile. Journal of Neurology, Neurosurgery, and Psychiatry, 57, 1334-1342. doi:10.1136/jnnp.57.11.1334

[27] Ropper, A.H. and Samuels, M.A. (2009) Principles of neurology. 9th Edition, McGraw-Hill Medical, New York. 